\title{
(6) OPEN ACCESS \\ The relationship between labour market categories and alcohol use trajectories in midlife
}

\author{
Esther Colell, ${ }^{1,2}$ Steven Bell, ${ }^{3}$ Annie Britton ${ }^{3}$
}

\begin{abstract}
${ }^{1}$ Drug Abuse Epidemiology Research Group, IMIM-Institut Hospital del Mar d'Investigacions Mèdiques, Barcelona, Spain

${ }^{2}$ Centre for Research in Occupational Health CiSAL, Universitat Pompeu Fabra, Barcelona, Spain

${ }^{3}$ Research Department of Epidemiology and Public Health, University College London, London, UK
\end{abstract}

Correspondence to Esther Colell, Drug Abuse Epidemiology Research Group, IMIM-Institut de Recerca Hospital del Mar, Doctor Aiguader 88, Barcelona E-08003, Spain ecolell@imim.es

Received 14 March 2014 Revised 13 June 2014 Accepted 1 July 2014 Published Online First 29 July 2014

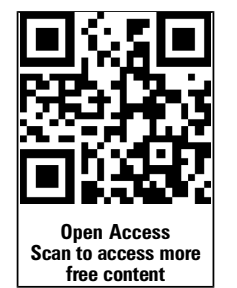

\begin{abstract}
Background and aims Studies on the role of labour market position and change in alcohol use during midlife are scarce and their results are inconclusive mainly due to their failure to define comprehensive and distinct labour market groups and the short periods of time studied. In this study we used different activity categories for men and women to examine alcohol use trajectories in midlife covering a period of 17 years.

Methods Using data from four sweeps of the National Child Development Study covering ages 33-50 ( $N=9960)$, we used multilevel growth models to study the association between labour market categories and longitudinal changes in weekly units of alcohol consumed.

Results In the reference group of full-time employed men alcohol trajectory decreased over the follow-up period ( $\beta=-0.14 ; 95 \% \mathrm{Cl}-0.18$ to -0.11$)$ while in the reference group of employed women it increased $(\beta=0.06 ; 95 \% \mathrm{Cl} 0.04$ to 0.08 ). Men and women who were 'mainly sick' had significantly steeper declines in their alcohol consumption trajectory. Women who became employed after being homemakers had the steepest increase in alcohol use $(\beta=0.05 ; 95 \% \mathrm{Cl} 0.01$ to 0.09 ).

Conclusions Being employed is a strong determinant of alcohol use for men and women in midlife, making the workplace a good target for health promotion programmes and policies aimed at reducing alcohol use. Caution is needed when interpreting the health effects of alcohol consumption as low alcohol users may have previously been heavy drinkers.
\end{abstract}

\section{INTRODUCTION}

It is believed that alcohol consumption tends to decrease with age ${ }^{1}$ and that drinking patterns are more stable for adults than for young people. ${ }^{2}$ Declines in alcohol consumption and alcohol problems from adolescence to adulthood have been generally explained as being the effect of 'role incompatibility', as involvement in new roles and activities (ie, family formation, parenthood and entry into paid employment) may interfere with a heavy drinking life style. ${ }^{3-5}$ This process has been referred to as 'maturing out'. ${ }^{6}$ Conversely, health problems have been consistently related to reductions in consumption or drinking cessation in elderly populations. ${ }^{7-11}$

The reasons for variations in alcohol use in midlife are less clear. Life transitions may not affect alcohol use in adulthood the way they do in younger people, and their effects may also vary by sex. ${ }^{12}{ }^{13}$ It is generally thought that more stable positions in an individual's life, like being employed, would result in reductions in alcohol use, whereas unemployment would result in increased consumption as it could be used for selfmedication purposes to cope with distress and anxiety. ${ }^{14}$ Conversely, while employment may provide more available income and opportunities to drink, long-term unemployment might be associated with a decrease in consumption due to a lack of financial resources to purchase alcohol. Furthermore, heavy alcohol use may also hinder the possibilities of getting a stable job and keeping it. These might be among the reasons why studies on trends in alcohol consumption in relation to changes in labour market status have yielded contradictory results. A meta-analysis of 12 longitudinal studies ${ }^{15}$ showed that becoming unemployed may lead to decreased alcohol use in older men and women, while young men may tend to increase consumption. Chronic unemployment was also associated with a decrease in alcohol consumption in older men and younger women, while becoming employed was related to increases in consumption among all age groups except young women. Similarly, loss of employment was not associated with increased drinking in a 5-year follow-up study of middle-aged men, and only those who became unemployed through illness were significantly more likely to reduce their drinking compared with those who remained employed. ${ }^{16}$ Conversely, in a 5 -year follow-up study, Virtanen $e t a l^{17}$ found that for men going from atypical employment or unemployment to permanent or fixed-term employment was associated with decreased alcohol use, whereas those with a downward trajectory or chronic unemployment tended to increase their alcohol intake. No associations were found between employment status and changes in alcohol use for women in this study. Furthermore, it has been suggested that employed women may drink more frequently or be more likely to report current alcohol consumption compared with those not in the labour market, ${ }^{18}{ }^{19}$ and that employed men and women may tend to drink more often than their unemployed counterparts. ${ }^{20}$

Some aspects must be considered when assessing the results of the studies above. Most of the longitudinal studies reviewed only considered changes over short periods of time (from 1 to 5 years), ${ }^{16} 17$ 20 and only 1 of the 13 studies in the meta-analysis by Temple $e t a l^{15}$ had more than a 10 -year interval between measurement occasions. Studies with a long period between measurements will be more able to capture changes in statuses as well as the effects of these changes on health-related behaviours such as drinking. However, a long interval may miss relevant variations between measurement points and be unable to determine the length of 
time spent in each status. Furthermore, exploring change in alcohol consumption with measures at only two points may be subject to some statistical issues (eg, regression to the mean) that the use of more measurements could circumvent. ${ }^{21}$

Most of the studies reviewed examined differences in alcohol consumption between employed and unemployed individuals, without distinguishing between those actively seeking a job from those that may be out of the labour market for other reasons. Social roles differ between men and women with women being primarily responsible for care work. This fact visibly affects their labour market participation and results in gendered employment patterns. Moreover, studies on alcohol use and labour market should take into account the complex link of health with occupation and alcohol use. According to the healthy worker effect, relatively healthy individuals are likely to obtain employment and to remain employed, while unhealthy people tend to have the shortest employment duration or be out of the workforce. ${ }^{22}$ Conversely, ill health may be behind a restriction or decrease of alcohol use. ${ }^{10}$

The objective of the present study was to examine change in individuals' labour market status as a predictor of alcohol consumption trajectories throughout midlife. For this purpose we studied a population-based cohort of men and women from ages 33-50 years, when the 'maturing out' process is likely to be over and alcohol use is more stable. We used information on activity status from four points in this period to define different labour market categories for men and women.

\section{METHODS}

\section{Source of information}

Data for this study were drawn from the National Child Development Study, also known as the 1958 British Birth Cohort Study, which follows the lives of 17000 people born in England, Scotland and Wales in a single week of 1958. Details of the cohort have been published elsewhere. ${ }^{23}$ Since the birth survey in 1958, there have been eight further sweeps at ages 7 , $11,16,23,33,42,46$ and 50. Despite sample attrition and some specific biases, such as a tendency for participants with less stable employment patterns and more disadvantaged circumstances to be more likely to be lost from the study, ${ }^{24}$ the sample remains broadly representative of the surviving cohort. ${ }^{25}$ For the purpose of this study we used information from four sweeps covering participants at ages 33, 42, 46 and 50. As only cohort members present in at least three sweeps were considered, 2921 men and 2337 women were excluded from the study. Excluded men and women were more likely to have lower educational attainment, be non-partnered and have higher malaise scores. Mean of weekly alcohol intake at age 33 was also higher among excluded men. The final analytic sample consisted of 4820 men and 5140 women.

\section{Labour market typologies}

Different activity trajectories were created for men and women based on their specific adherence to the labour market and home responsibilities. Men's link with the labour market is more stable, while women exhibit significant movements in and out of the workforce, especially related to care work within the family sphere. ${ }^{26}$ Besides, the vast majority of men in employment work full-time (FT), while women are significantly more likely to be in part-time (PT) work. ${ }^{27}$ PT work might help women combine work and home responsibilities, whereas for men working PT, as an atypical working arrangement linked to precarious conditions, ${ }^{28}$ might indicate a failure to obtain a FT job. PT employment as well as unemployment may be indicative of employment instability in men. Conversely, the relative importance of unemployment in women's trajectories compared with other positions and the need to construct meaningful trajectories prompted the omission of unemployment in the typologies created for women.

Defined categories for men were: (1) mainly FT employed: FT employed in at least three sweeps; (2) mainly PT or unemployed: PT employed in at least three sweeps, or unemployed in at least three sweeps, or $2 \times 2$ combinations of PT and unemployment; (3) became unstable: FT employed at age 33 and 42 and PT or unemployed at age 46 and 50 or at age 50 only; (4) mainly sick or became sick: sick/disabled in at least three sweeps; or any activity at age 33 and 42 and sick/disabled at age 46 and 50; and (5) other: men with an irregular labour market pattern who could not be included in any of the above categories. Categories for women were: (1) mainly employed: either FT or PT employed in at least three sweeps; (2) mainly homemaker: homemaker in at least three sweeps; (3) from employed to homemaker: either FT or PT employed at age 33 and 42 and homemaker at age 46 and 50 or at age 50 only; (4) from homemaker to employed: homemaker at age 33 or at age 33 and 42 and either FT or PT employed at age 46 and 50 only; (5) mainly sick or became sick: sick/disabled in at least three sweeps or any activity at age 33 and 42 and sick/disabled at age 46 and 50; and (6) other: women with an irregular labour market pattern who could not be included in any of the above categories.

\section{Alcohol consumption}

Alcohol consumption was defined in terms of UK units of alcohol consumed in the past week at ages 33, 46 and 50. Data from age 42 were not used due to errors in the data collection process. ${ }^{29}$ Participants who reported drinking in the previous week were asked to provide information on the quantity of the different alcoholic beverages they consumed (at age 46 the question referred to an average week). The reported information was converted into standard UK units ( 1 unit $=8 \mathrm{~g}$ of pure ethanol) using a conservative conversion rate of 2 UK units for a pint of beer/cider and 1 UK unit for all other beverages. Participants who reported no consumption were assigned a 0.

\section{Covariates}

Information on participants' partner status ${ }^{13}$ (cohabiting with a partner either married or not) was recorded at each age. The malaise inventory ${ }^{30}$ was used to measure psychological distress or tendency towards non-clinical depression at age $33 .{ }^{31}$ Highest qualifications gained at age $33^{32}$ were recoded into three categories according to the International Standard Classification of Education (ISCED 2011): low (primary and lower secondary education), intermediate (upper secondary and postsecondary education) and high (from short-cycle tertiary education onwards), used as reference category.

\section{Analysis}

We used multilevel growth models to examine the association of activity categories in midlife on longitudinal change in weekly units of alcohol consumed. Growth models describe trajectories in terms of intercept and slope effects, allowing variance within and between individuals.

Unconditional growth models (allowing for random intercepts and slopes) for units of alcohol consumed from age 33-50 with an interaction between activity typologies and time were fitted separately for men and women. Those mainly FT employed were used as the reference category for men and those mainly 
employed for women. Additional models incorporating each of the covariates were estimated and likelihood ratio tests were used to determine whether the inclusion of each covariate improved model fit. Partner status was included as a timevarying covariate whereas highest qualifications and mental health at baseline were included as time-invariant predictors. For men, the final adjusted model included only partner status while for women highest qualification and mental health at age 33 were also included. Given the availability of only three measures of alcohol consumption change was estimated to be linear. Random effects were allowed to co-vary. All analyses were conducted using Stata V.12 (StataCorp, College Station, Texas, USA) using a maximum likelihood algorithm.

\section{RESULTS}

The descriptive characteristics of the sample are presented in table 1 . Almost $85 \%$ of male cohort members belonged to the FT employed category, while in women those mainly employed accounted for $62 \%$ of the total sample. With respect to alcohol use, men's average weekly units at age 33 was three times higher than that of women, and at ages 46 and 50 it was more than double $(16.7(\mathrm{SD}=19.8), 12.7(\mathrm{SD}=15.5)$ and $14.3(\mathrm{SD}=6.7)$ vs $4.9(\mathrm{SD}=7.6), 5.8(\mathrm{SD}=7.7)$ and $6.1(\mathrm{SD}=8.4))$. In the case of the covariates, $50 \%$ of men and $63 \%$ of women had only acquired low qualifications at age 33 , with the lowest rates among those mainly employed and the highest among the sick in both sexes. Women had poorer mental health at age 33 than men $(8.4 \%$ vs $3.6 \%$ at high risk of psychological distress). The risk of psychological distress was highest in the sick category in men and women (20\% and 31\%, respectively), and for women those that became homemakers and mainly homemakers also rated high (18\% and 12\%). Finally, the percentage of those living with a partner at age 33 was similar in men and women, with the highest rates within the mainly employed among men and within those that became employed among women; the lowest rates of partnered individuals were among the sick group in both sexes.

Table 2 shows estimates of the intercepts (values at age 33) and slopes describing age-related linear changes in alcohol consumption in the longitudinal labour market typologies (per year increase in age, centred at age 33). Average consumption at age 33 of the reference category of men (mostly FT employed) was 15.84 units per week (95\% CI 15.23 to 16.45 ) with an average decline of 0.14 units per unit increase in age $(95 \% \mathrm{CI}-0.18$ to -0.11 ). For women, those who remained mostly in employment had an average intake of 5.40 units at age 33 (95\% CI 5.13 to $5.67)$ but increased their consumption at a rate of 0.06 units a year (95\% CI 0.04 to 0.08 ).

In men, those who were mainly sick (or became sick) during follow-up typically drank almost four more units at age 33 than the reference category of those mainly in FT employment $(\beta=3.96,95 \%$ CI 0.42 to 7.51$)$ and made a more rapid decline in their consumption over time $(\beta=-0.36,95 \%$ CI -0.57 to $-0.15)$. The significant effect observed for the intercept was attenuated after adjusting for partner status (the $p$ value fell outside the conventional threshold of 0.05 used for significance testing but there was evidence of borderline statistical significance $(p=0.075))$ and remained significant for the slope. Similarly, those belonging to the 'Other' category typically consumed more alcohol at age $33(\beta=3.50,95 \%$ CI 1.44 to 5.57$)$ and made greater declines in their drinking over time $(\beta=$ $-0.15,95 \%$ CI -0.28 to -0.02 ) than the mainly FT-employed group, an effect which remained significant after adjusting for partnership status. The estimates for those mainly PT or

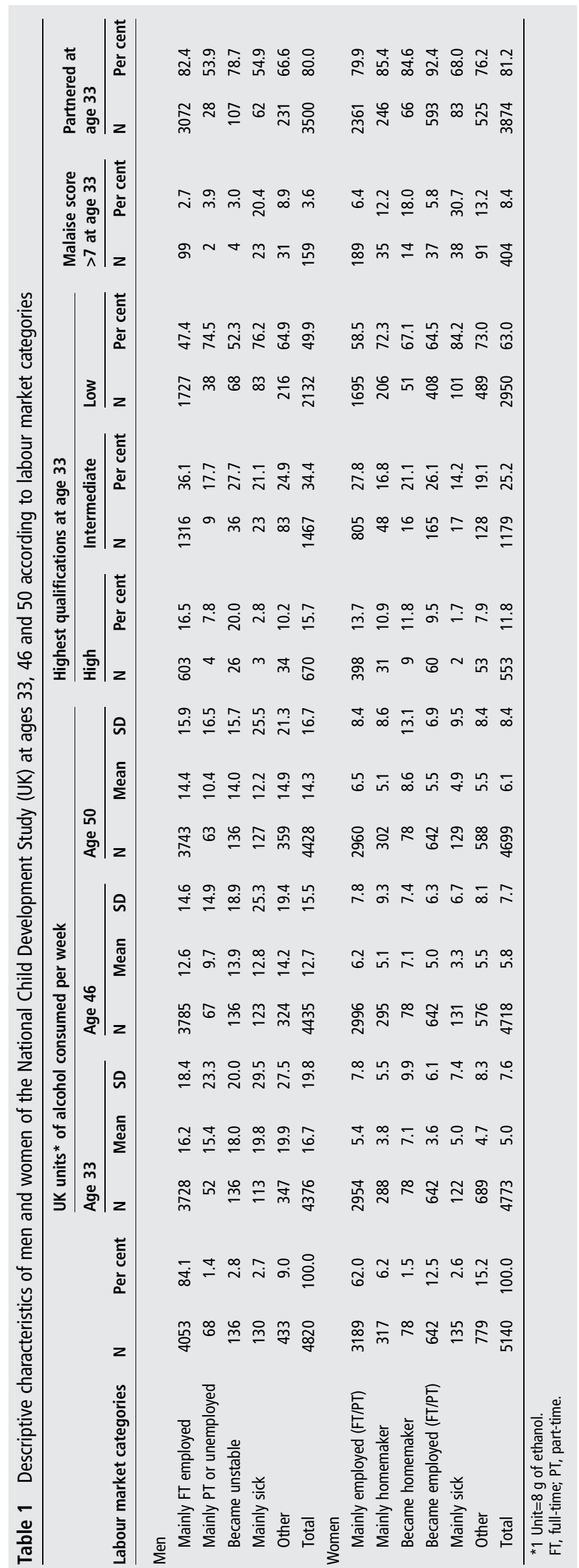


Table 2 Fixed effects of unconditional and adjusted growth models of weekly alcohol consumption from age 33-50 by labour market category for men and women of the National Child Development Study (UK)

\begin{tabular}{|c|c|c|c|c|c|c|c|c|}
\hline & \multicolumn{4}{|c|}{ Unconditional model } & \multicolumn{4}{|c|}{ Adjusted model* } \\
\hline & $\boldsymbol{\beta}$ & $95 \% \mathrm{Cl}$ & & $\mathrm{p}$ Value & $\boldsymbol{\beta}$ & $95 \% \mathrm{Cl}$ & & p Value \\
\hline \multicolumn{9}{|l|}{ Men } \\
\hline Intercept† & 15.84 & 15.23 & 16.45 & 0.000 & 15.46 & 14.83 & 16.08 & 0.000 \\
\hline Mainly full-time employed & (ref.) & & & & (ref.) & & & \\
\hline Mainly part-time or unemployed & -1.16 & -6.26 & 3.93 & 0.655 & -1.72 & -6.81 & 3.36 & 0.507 \\
\hline Became unstable & 1.98 & -1.33 & 5.29 & 0.241 & 1.90 & -1.39 & 5.20 & 0.257 \\
\hline Mainly sick or became sick & 3.96 & 0.42 & 7.51 & 0.028 & 3.22 & -0.33 & 6.76 & 0.075 \\
\hline Other & 3.50 & 1.44 & 5.57 & 0.001 & 3.17 & 1.11 & 5.23 & 0.003 \\
\hline Slopeł & -0.14 & -0.18 & -0.11 & 0.000 & -0.14 & -0.18 & -0.11 & 0.000 \\
\hline Mainly full-time employed & (ref.) & & & & (ref.) & & & \\
\hline Mainly part-time or unemployed & -0.17 & -0.48 & 0.15 & 0.298 & -0.16 & -0.47 & 0.15 & 0.321 \\
\hline Became unstable & -0.11 & -0.31 & 0.09 & 0.273 & -0.11 & -0.30 & 0.09 & 0.283 \\
\hline Mainly sick or became sick & -0.36 & -0.57 & -0.15 & 0.001 & -0.36 & -0.58 & -0.15 & 0.001 \\
\hline Other & -0.15 & -0.28 & -0.02 & 0.024 & -0.16 & -0.29 & -0.04 & 0.012 \\
\hline No cohabiting partner & & & & & 2.18 & 1.41 & 2.96 & 0.000 \\
\hline \multicolumn{9}{|l|}{ Women } \\
\hline Intercept $†$ & 5.40 & 5.13 & 5.67 & 0.000 & 6.32 & 5.77 & 6.87 & 0.000 \\
\hline Mainly employed (full-time/part-time) & (ref.) & & & & (ref.) & & & \\
\hline Mainly homemaker & -1.67 & -2.57 & -0.76 & 0.000 & -1.43 & -2.33 & -0.52 & 0.002 \\
\hline From employed to homemaker & 1.56 & -0.14 & 3.26 & 0.073 & 1.30 & -0.39 & 2.99 & 0.132 \\
\hline From homemaker to employed & -1.81 & -2.45 & -1.16 & 0.000 & -1.65 & -2.28 & -1.01 & 0.000 \\
\hline Mainly sick or became sick & -0.52 & -1.87 & 0.84 & 0.456 & -0.81 & -2.18 & 0.56 & 0.246 \\
\hline Other & -0.66 & -1.28 & -0.04 & 0.037 & -0.59 & -1.22 & 0.03 & 0.064 \\
\hline High qualifications & & & & & (ref.) & & & \\
\hline Medium qualification & & & & & -1.03 & -1.65 & -0.40 & 0.001 \\
\hline Low qualifications & & & & & -1.42 & -1.98 & -0.85 & 0.000 \\
\hline Malaise score $>7$ & & & & & 0.92 & 0.13 & 1.70 & 0.022 \\
\hline Slope‡ & 0.06 & 0.04 & 0.08 & 0.000 & 0.06 & 0.04 & 0.08 & 0.000 \\
\hline Mainly employed (full-time/part-time) & (ref.) & & & & (ref.) & & & \\
\hline Mainly homemaker & 0.02 & -0.04 & 0.08 & 0.529 & 0.02 & -0.04 & 0.08 & 0.488 \\
\hline From employed to homemaker & 0.00 & -0.11 & 0.12 & 0.972 & 0.02 & -0.09 & 0.14 & 0.684 \\
\hline From homemaker to employed & 0.05 & 0.01 & 0.09 & 0.024 & 0.05 & 0.01 & 0.09 & 0.025 \\
\hline Mainly sick or became sick & -0.11 & -0.20 & -0.02 & 0.019 & -0.10 & -0.19 & 0.00 & 0.046 \\
\hline Other & -0.01 & -0.06 & 0.03 & 0.559 & -0.01 & -0.06 & 0.03 & 0.521 \\
\hline No cohabiting partner & & & & & 0.50 & 0.16 & 0.83 & 0.004 \\
\hline Malaise score $>7$ & & & & & -0.06 & -0.11 & 0.00 & 0.035 \\
\hline
\end{tabular}

unemployed, and those who became unstable over time were non-significant.

Like in men, women who were mainly sick throughout observation also made greater reductions in their alcohol intake over time $(\beta=-0.11,95 \% \mathrm{CI}-0.20$ to -0.02$)$, however, unlike men, this group did not significantly differ in their weekly alcohol intake at age $33(\beta=-0.52,95 \% \mathrm{CI}-1.87$ to 0.84$)$ than those who remained in employment throughout follow-up. Those who made the transition from homemaker to employment during follow-up consumed less alcohol on average at age 33 $(\beta=-1.81,95 \%$ CI -2.45 to -1.16$)$ than those mostly employed, however, they increased their intake over time at a greater rate $(\beta=0.05,95 \%$ CI 0.01 to 0.09$)$. Those who were mainly homemakers throughout follow-up on average drank less alcohol at age $33(\beta=-1.67,95 \%$ CI -2.57 to -0.76$)$ than the mainly employed group, but did not significantly differ in their rate of change in consumption over time.
Figure 1 illustrates predicted alcohol trajectories from age 33-50 by labour market category for men and women. Note that the scale of the $y$-axis on each graph differs. In men, all categories displayed a downward trajectory of alcohol consumption. In women, all labour market groups displayed an upward trend in alcohol intake except the sick group which made significant declines in their drinking.

\section{DISCUSSION}

The present study used repeated longitudinal measures to examine individuals' labour market categories as predictors of weekly alcohol consumption at age 33 and the rate of change in drinking across midlife. Our findings show different trends in alcohol intake for men and women. In men, alcohol consumption typically declined while women made modest increases in their intake from age 33 through 50. The main findings regarding different activity categories are that those mainly sick or 
Figure 1 Predicted alcohol trajectories from ages 33 to 50 by labour market category for men and women of the National Child Development Study (UK).
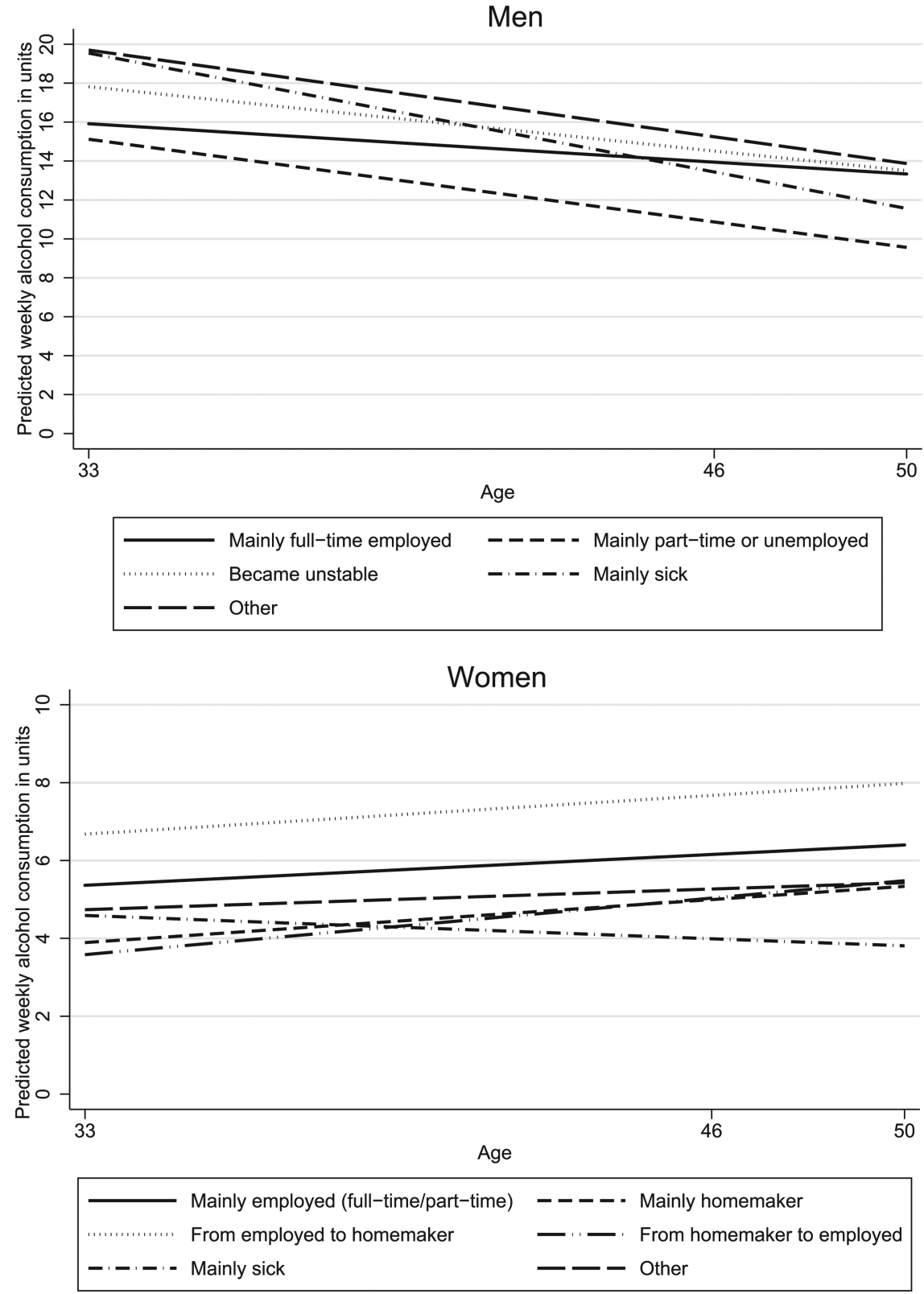

becoming sick made substantial declines in their alcohol consumption in both sexes. Conversely, women becoming employed significantly increased their alcohol use compared with those that remained in the workforce.

The different trends in consumption observed between men and women during the period could be explained by the fact that men's drinking level at age 33 is still influenced by larger amounts of alcohol use at younger age, and that decreases in alcohol use due to 'maturing out' are still in progress. Conversely, women may increase their alcohol use after lower levels of intake due to pregnancy and motherhood. ${ }^{33}$ Noteworthy, $81 \%$ of the women in this sample had children at home at age 33 (data not shown).

Our finding that those mainly sick made significant declines in their alcohol intake is supported by other studies that have reported health-related declines in alcohol use. ${ }^{7-10}$ We observed that men who were mainly sick during follow-up consumed significantly more alcohol at age 33 and experienced steeper declines in consumption over time. This finding supports the need to consider the role of ill health and of former heavy drinking in studies using only current level of alcohol use. ${ }^{34}$ However, it needs to be mentioned that in order to reach appropriate statistical power, the sick category used in our study combined those mainly sick with those who became sick during follow-up. It would have been preferable to examine both groups separately as it is possible that the higher alcohol intake in this group at age 33 is largely driven by those who became sick during follow-up, as those who were sick at baseline may have already been drinking lower amounts.

With respect to women, our findings are supported by those of previous studies which found an increased level of alcohol use among employed women compared with those not in the labour market. ${ }^{18}{ }^{19}$ Although the mechanisms linking employment to women's drinking behaviour are complex, it has been suggested that while responsibility for others (eg, caring for young children) would be incompatible with alcohol consumption, work outside the home may provide women with more available income and opportunities to drink. ${ }^{35}$ Furthermore, 
our findings suggest that homemakers entering the workforce significantly increase their alcohol intake, although the effect size is very modest. However, sensitivity analysis using those that became employed as the reference category showed that their rate of change did not differ from those that remained homemakers (data not shown). This suggests that leaving behind pregnancy and responsibility for small children may have more influence on increasing alcohol use than employment.

The findings of this study show other interesting relationships between activity grouping and drinking trajectory although they are not considered statistically significant. FT-employed men that became unstable (PT or unemployed) at the end of the period had higher weekly alcohol use at age 33 than those who stayed in FT employment. It has been argued that heavy drinking may increase the risk of downward mobility or unemployment. ${ }^{37}$ Conversely, men that remained PT or unemployed throughout the period had a lower level of alcohol use at baseline and declined at a greater rate. Lower levels of alcohol use have also been found in other studies among men with weak links with the labour market. ${ }^{15} 2038$ Besides, poor health as the reason for weak engagement with the labour market ${ }^{39}$ that would also account for the lower drinking level within this group cannot be ruled out.

The strengths of our study mainly lie in its prospective longitudinal design, the length of the follow-up period, the large sample size and the use of several measurement occasions to define activity typologies and estimate alcohol consumption trajectories. Conversely, even though we used data on a large sample of individuals, the analysis was limited by the small size of some groups. Although we tried to incorporate the most relevant categories for men and women, some meaningful ones were not large enough to further stratify the sample. For example, as described above, separating those mainly sick throughout the period from those who became ill would have been particularly relevant. It also needs to be mentioned that our alcohol trajectories were based on estimated mean alcohol consumption levels, and that future work should consider the associations of labour market transitions with heavy alcohol use or alcohol-related disorders. Furthermore, the way we constructed labour market categories and linked those to alcohol intake over time did not consider the dynamic interplay between the two over time, and this would be an interesting avenue for future work.

Finally, some caution must be applied as to the extent to which these results can be extrapolated to the present general population. Our study population is based on a British cohort of men and women born in 1958 that does not have the ethnic diversity of today's population, although it remains broadly representative of the general population of that time, and the activity typologies examined are largely applicable to contemporary population. Furthermore, some sociocultural and historical factors may affect the observed level of alcohol use of this cohort that may differ from that of other birth cohorts. ${ }^{1}$ According to the results of a trend analysis to disentangle age, period and birth cohort effects in alcohol consumption level in Great Britain $^{40}$ it is possible that younger cohorts may reach lower levels of alcohol use than those described in this paper.

This study contributes to a better understanding of alcohol trajectories in midlife by examining the associations of different labour market categories on alcohol use and we found that being employed is a strong determinant of alcohol use for men and women. Employment is a core activity for most of the population during midlife and its importance to structure people's life and to establish patterns of sociability make the workplace a good target for programmes focused on health promotion and policies aimed at reducing alcohol use.

\section{What is already known on this subject}

The effect of life transitions in variation of alcohol use in midlife is not clear and studies on trends in alcohol consumption in relation to changes in labour market have yielded contradictory results.

\section{What this study adds}

Overall alcohol consumption in midlife declines for men and increases for women. Men as well as women who were mainly sick made significant reductions in their alcohol consumption, illustrating the 'sick-quitting' effect. Women entering the labour market after being a homemaker had the steepest increase in alcohol use over time.

Contributors EC, SB and $A B$ devised the research question. EC analysed data and completed first draft of the manuscript. $S B$ and $A B$ provided important additional comments on the initial manuscript. EC, SB and $A B$ agreed on the decision to submit the final manuscript. Each author certifies that he or she has participated sufficiently in the work to believe in its overall validity and to take public responsibility for appropriate portions of its content.

Funding This work was supported by Delegación del Gobierno para el Plan Nacional sobre Drogas, Ministerio de Salud y Política Social (Grant number: PNSD 2011/I073); FIS-Redes de investigación cooperativa (Grant number RD12/0028/ 0018). AB and SB were funded by the European Research Council (309337, PI: Britton, http://www.ucl.ac.uk/alcohol-lifecourse).

\section{Competing interests None.}

Provenance and peer review Not commissioned; externally peer reviewed.

Open Access This is an Open Access article distributed in accordance with the Creative Commons Attribution Non Commercial (CC BY-NC 4.0) license, which permits others to distribute, remix, adapt, build upon this work non-commercially, and license their derivative works on different terms, provided the original work is properly cited and the use is non-commercial. See: http://creativecommons.org/ licenses/by-nc/4.0/

\section{REFERENCES}

1 Johnstone $\mathrm{BM}$, Leino $\mathrm{EV}$, Ager $\mathrm{CR}$, et al. Determinants of life-course variation in the frequency of alcohol consumption: meta-analysis of studies from the collaborative alcohol-related longitudinal project. I Stud Alcohol 1996;57:494-506.

2 Kerr WC, Fillmore KM, Bostrom A. Stability of alcohol consumption over time: evidence from three longitudinal surveys from the United States. I Stud Alcohol 2002;63:325-33.

3 Dawson DA, Grant BF, Stinson FS, et al. Maturing out of alcohol dependence: the impact of transitional life events. J Stud A/cohol 2006;67:195-203.

4 Bogart LM, Collins RL, Ellickson PL, et al. Effects of early and later marriage on women's alcohol use in young adulthood: a prospective analysis. J Stud Alcohol 2005;66:729-37.

5 Gotham HJ, Sher KJ, Wood PK. Alcohol involvement and developmental task completion during young adulthood. I Stud Alcohol 2003;64:32-42.

6 O'Malley PM. Maturing out of problematic alcohol use. Alcohol Res Health 2004;28:202-4.

7 Dawson DA, Goldstein RB, Grant BF. Prospective correlates of drinking cessation: variation across the life-course. Addiction 2013;108:712-22.

8 Molander RC, Yonker JA, Krahn DD. Age-related changes in drinking patterns from mid- to older age: results from the Wisconsin longitudinal study. Alcohol Clin Exp Res 2010;34:1182-92.

9 Walton MA, Mudd SA, Blow FC, et al. Stability in the drinking habits of older problem-drinkers recruited from nontreatment settings. I Subst Abuse Treat 2000;18:169-77. 
10 Wannamethee G, Shaper AG. Changes in drinking habits in middle-aged British men. J R Coll Gen Pract 1988;38:440-2.

11 Platt A, Sloan FA, Costanzo P. Alcohol-consumption trajectories and associated characteristics among adults older than age 50. J Stud Alcohol Drugs 2010;71:169-79.

12 Verges A, Jackson KM, Bucholz KK, et al. Deconstructing the age-prevalence curve of alcohol dependence: why "maturing out" is only a small piece of the puzzle. J Abnorm Psychol 2012;121:511-23.

13 Neve RJ, Lemmens PH, Drop MJ. Changes in alcohol use and drinking problems in relation to role transitions in different stages of the life course. Subst Abus 2000;21:163-78

14 Ettner SL. Measuring the human cost of a weak economy: does unemployment lead to alcohol abuse? Soc Sci Med 1997;44:251-60.

15 Temple MT, Fillmore KM, Hartka $\mathrm{E}$, et al. A meta-analysis of change in marital and employment status as predictors of alcohol consumption on a typical occasion. Br J Addict 1991;86:1269-81.

16 Morris JK, Cook DG, Shaper AG. Non-employment and changes in smoking, drinking, and body weight. BMJ 1992;304:536-41.

17 Virtanen P, Vahtera J, Broms U, et al. Employment trajectory as determinant of change in health-related lifestyle: the prospective HeSSup study. Eur J Public Health 2008:18:504-8.

18 Parker DA, Parker ES, Wolz MW, et al. Sex roles and alcohol consumption: a research note. J Health Soc Behav 1980;21:43-8.

19 Ebi-Kryston KL, Higgins MW, Keller JB. Health and other characteristics of employed women and homemakers in Tecumseh, 1959-1978. I. Demographic characteristics, smoking habits, alcohol consumption, and pregnancy outcomes and conditions. Women Health 1990;16:5-21.

20 Lahelma E, Kangas R, Manderbacka K. Drinking and unemployment: contrasting patterns among men and women. Drug Alcohol Depend 1995;37:71-82.

21 Singer JD, Willett JB. Applied longitudinal data analysis: modeling change and event occurrence. New York: Oxford University Press, 2003.

22 Pearce $\mathrm{N}$, Checkoway $\mathrm{H}$, Kriebel D. Bias in occupational epidemiology studies. Occup Environ Med 2007;64:562-8.

23 Power C, Elliott J. Cohort profile: 1958 British birth cohort (National Child Development Study). Int J Epidemiol 2006;35:34-41.

24 Hawkes D, Plewis I. Modelling non-response in the National Child Development Study. JR Stat Soc 2006;169:479-91.

25 Atherton K, Fuller E, Shepherd P, et al. Loss and representativeness in a biomedical survey at age 45 years: 1958 British birth cohort. J Epidemiol Community Health 2008:62:216-23.
26 Hynes K, Clarkberg M. Women's employment patterns during early parenthood: a group-based trajectory analysis. J Marriage Fam 2005;67:222-39.

27 Office for National Statistics. Labour Market Statistics. http://www.ons.gov.uk

28 Hinterseer T. Part-time work: Atypical? Precarious? Normal? Eur J Futures Res 2013;1:18.

29 Centre for Longitudinal Studies. Possible over-reporting of beer consumption. Data notes. 2012. http://www.cls.ioe.ac.uk/page.aspx?\&sitesectionid=771\& sitesectiontitle $=$ data+notes accessed (Apr 2014).

30 Rutter M, Tizard J, Whitmore K. Education, health and behaviour. London: Longmans, 1970

31 Swendsen JD, Merikangas KR. The comorbidity of depression and substance use disorders. Clin Psychol Rev 2000:20:173-89.

32 Lee JO, Herrenkohl TI, Kosterman R, et al. Educational inequalities in the co-occurrence of mental health and substance use problems, and its adult socio-economic consequences: a longitudinal study of young adults in a community sample. Public Health 2013:127:745-53.

33 Bachman JG, Wadsworth KN, O'Malley PM, et al. Smoking, drinking, and drug use in young adulthood: the impacts of new freedoms and new responsibilities. Mahwah, NJ: Lawrence Erlbaum Associates, 1997.

34 Fillmore KM, Stockwell T, Chikritzhs T, et al. Moderate alcohol use and reduced mortality risk: systematic error in prospective studies and new hypotheses. Ann Epidemiol 2007;17(5 Suppl):S16-23.

35 Wilsnack RW, Cheloha R. Women's roles and problem drinking across the lifespan. Soc Probl 1987;34:231-48

36 Wilsnack RW, Wilsnack SC. Women, work, and alcohol: failures of simple theories. Alcohol Clin Exp Res 1992;16:172-9.

37 Romelsjo A, Stenbacka M, Lundberg M, et al. A population study of the association between hospitalization for alcoholism among employees in different socio-economic classes and the risk of mobility out of, or within, the workforce. Eur J Public Health 2004:14:53-7.

38 Moore AA, Gould R, Reuben DB, et al. Longitudinal patterns and predictors of alcohol consumption in the United States. Am J Public Health 2005;95:458-65.

39 Virtanen $\mathrm{P}$, Vahtera J, Kivimaki $\mathrm{M}$, et al. Labor market trajectories and health: a four-year follow-up study of initially fixed-term employees. Am J Epidemiol 2005:161:840-6.

40 Meng Y, Holmes J, Hill-McManus D, et al. Trend analysis and modelling of gender-specific age, period and birth cohort effects on alcohol abstention and consumption level for drinkers in Great Britain using the General Lifestyle Survey 1984-2009. Addiction 2014;109:206-15. 